\title{
COMPARAÇÃO DE TRÊS MÉTODOS DE OBTENÇÃO DE DADOS PARA AVALIAÇÃO QUALI-QUANTITATIVA DA ARBORIZAÇÃO VIÁRIA, EM BELO HORIZONTE-MG ${ }^{1}$.
}

Aderbal Gomes da Silva², Wantuelfer Gonçalves ${ }^{3}$, Hélio Garcia Leite ${ }^{3}$, e Ednilson dos Santos ${ }^{4}$

\section{RESUMO}

Este estudo teve como objetivo comparar três métodos de obtenção de dados para se avaliar a qualidade da arborização de ruas. As três formas de obtenção de dados foram denominadas de Método I, Método II e Método III. O estudo foi desenvolvido na cidade de Belo Horizonte-MG, abrangendo os bairros Horto e Sagrada Família. Foram avaliados a precisão dos métodos, o tempo gasto e os recursos necessários para a sua execução. A execução do Método I foi 2,4 vezes mais rápida que a do Método III e 1,6 vezes mais rápida que a execução do Método II. Já o tempo gasto para a realização do Método II, foi 1,5 vezes menor do que aquele gasto para a realização do Método III. Os custos de realização do Método III foram 5,4 vezes mais elevados que os custos de realização do Método I e 2,6 vezes maiores que aqueles do Método II. Já para a realização do Método II, gastou-se o dobro de recursos em relação ao Método I.

Palavras-chave: arborização urbana, métodos de inventário e precisão do inventário.

\footnotetext{
1. Parte da tese de doutorado do primeiro autor apresentada ao Programa de Pós-Graduação do Curso de Ciência Florestal da Universidade Federal de Viçosa - UFV.

2. Prof. do Departamento de Engenharia Florestal da Universidade Federal do Espírito SantoCCA/UFES, Alegre-ES, aderbalsilva@yahoo.com.br.

3. Prof. do Departamento de Engenharia Florestal da UFV, 36571-000 Viçosa-MG.

${ }^{4}$. Secretaria de Meio Ambiente e Saneamento Urbano de Belo Horizonte, MG.
} 


\title{
COMPARISON OF THREE METHODS OF OBTAINING DATA FOR QUALI- QUANTITATIVE EVALUATION OF STREET ARBORIZATION, IN BELO HORIZONTE-MG.
}

\begin{abstract}
This study had as objective compares three methods of obtaining of data to evaluate the quality of the streets arborization. The three forms of obtaining data were called Method I, Method II and Method III. The study was developed in the city of Belo Horizonte-MG, embracing the zones called Horto and Sagrada Família. Were appraised the precision of the methods, the time spends and the resources for your execution. The Method I execution, was 2,4 times more rapid than Method III and 1,6 times more rapid than Method II. The time spends for execution of the Method II, it was 1,5 times minor than that spends for the Method III. The costs of execution of the Method III were 5,4 times higher than the costs of execution of the Method I and 2,6 times bigger than for the Method II. For the execution of the Method II spent the double of the resources of the Method I
\end{abstract}

Key-words: urban arborization, inventory methods and precision of the inventory. 


\section{INTRODUÇÃO}

A arborização urbana, para propiciar benefícios à população, exige um planejamento criterioso e um manejo adequado. Para tal, faz-se necessário conhecer o patrimônio arbóreo, o que facilita a manutenção de uma arborização de qualidade.

No Brasil, o que ocorre na maioria das vezes, salvo raras exceções, é que a arborização urbana não passa por um planejamento prévio, embora essa mentalidade esteja aos poucos se modificando. Resta então, a correção dos erros já constatados e a potencialização das ações notoriamente bem sucedidas (SANTOS, 2001). Por meio de um inventário é possível verificar os erros e acertos na arborização de uma cidade.

A importância do inventário está no fato de que através dele pode-se conhecer o patrimônio arbóreo e identificar as necessidades de manejo. Um dos aspectos mais importantes do inventário é quando este é realizado de forma a fornecer uma contínua atualização das informações (TAKAHASHI, 1994).

O inventário, dada a sua grande abrangência, pode funcionar como um poderoso instrumento de esclarecimento e persuasão dos administradores e usuários do local inventariado (MILLER, 1997).

Tão importante como definir a abrangência do inventário, é a definição da metodologia a ser aplicada na coleta dos parâmetros, enfatizando a sua intensidade, ou seja, se estes serão medidos integralmente, ou parcialmente, e se serão agrupados em classes de valores ou preservados os valores originais.

As informações a serem coletadas dependem basicamente dos objetivos do inventário e da disponibilidade de recursos.

Os inventários para avaliação da arborização de ruas podem ser de caráter quantitativo, qualitativo ou quali-quantitativo (MILANO, 1988). Quanto mais complexos forem, maior será o custo de realização.

Tendo em vista que cada informação tem um custo, cabe ao planejador definir criteriosamente suas reais necessidades, uma vez que se constata a realização de inventários extremamente complexos e dispendiosos, completamente esquecidos nas gavetas (TAKAHASHI, 1990).

As características e parâmetros a serem avaliados devem abordar alguns pontos básicos tais como: localização da árvore (nome da rua, bairro, número da casa); características da árvore (espécie, porte, fitossanidade) e características do meio (largura de ruas e passeios, espaçamento do plantio, pavimentação dos passeios, presença de redes de serviços, afastamento predial, tipo de forração na área de crescimento).

Este trabalho tratou especificamente das formas de coleta de dados e teve como objetivo comparar três tipos de inventário para avaliação quali-quantitativa da arborização urbana viária, sendo estes: o Método I, no qual os parâmetros foram estimados visualmente 
sem a utilização de qualquer aparelho de medição; o Método II, que usou as estruturas urbanas como referência para a tomada das medidas; e o Método III, onde os parâmetros quantitativos foram completamente mensurados e anotados os valores exatos.

\section{MATERIAIS E MÉTODOS}

\section{Área de estudo}

A cidade de Belo Horizonte situa-se a $19^{\circ} 55^{\prime}$ de latitude Sul e a $43^{\circ} 56^{\prime}$ de longitude Oeste e sua altitude aproximada é de $875 \mathrm{~m}$. O clima local apresenta estações secas e úmidas bem definidas. O período úmido é também o mais quente e se estende de outubro a março. A temperatura média é de $21,7^{\circ} \mathrm{C}$, podendo atingir valores de até $26,8^{\circ} \mathrm{C}$ na estação mais quente e de $16^{\circ} \mathrm{C}$ na estação mais fria. As temperaturas máximas podem se apresentar entre $33^{\circ}$ e $40^{\circ} \mathrm{C}$, enquanto as mínimas podem descer aos limites de $5^{\circ} \mathrm{C}$. A pluviosidade média anual é de 1505,7 mm (CENCIC, 1996).

O estudo foi desenvolvido na Região Administrativa Leste (RAL), que é uma das nove regionais em que a cidade está dividida. As Regionais funcionam como sub-prefeituras.

O trabalho avaliou uma amostra dos indivíduos arbóreos e arbustivos existentes em passeios públicos dos bairros Horto e Sagrada Família. As ruas inventariadas foram selecionadas por meio de sorteio e cada rua contemplada foi avaliada em toda a sua extensão ou até o limite da RAL.

\section{Inventário quali-quantitativo}

A coleta dos dados foi realizada por uma equipe, cuja formação variou de acordo com o método utilizado. Para cada um dos três tipos de inventário, foram coletadas informações sobre todos os parâmetros, variando apenas a forma de sua obtenção.

Na execução do Método I, um avaliador (técnico de nível superior) estimou a olho nu, sem qualquer instrumento de medição, todos os parâmetros. Os valores obtidos foram distribuídos em classes.

No Método II, os dados foram coletados por uma equipe composta de um anotador (técnico de nível superior) e dois auxiliares de medição. Os valores dos parâmetros DAP, avanço da copa sobre a rua e largura do passeio foram determinados com auxílio de uma trena, na qual foram colocados marcadores destacando os intervalos das classes. A altura total foi estimada mediante a referência da altura de postes e redes de distribuição de energia elétrica. Os demais parâmetros não mensuráveis foram preenchidos de acordo com a avaliação do anotador. Os valores obtidos foram distribuídos em classes, da mesma forma que no Método I. 
Por último, foram realizadas as medições dos parâmetros, utilizando o Método III, isto para se evitarem os erros de tendência, que poderiam ser cometidos, se este fosse realizado primeiro. Os dados mensuráveis foram determinados com o auxílio de trena e uma régua retrátil, usadas pela mesma equipe do Método II. Os valores exatos foram anotados na ficha de coleta. Os dados não mensuráveis foram preenchidos, conforme avaliação do anotador. Os parâmetros e características selecionados para avaliação estão de acordo com as recomendações de GREY e DENEKE (1986), MILANO (1988) e SANTOS (2001). Esses foram considerados de fundamental importância para o conhecimento da qualidade da arborização urbana, sendo contempladas: espécie, altura total, altura da primeira bifurcação, diâmetro do tronco a 1,30 m de altura (DAP), avanço da copa sobre a rua, avanço da copa sobre a construção, fitossanidade, condição do sistema radicular, área de crescimento ou área livre para engrossamento do tronco, largura do passeio e fiação aérea.

\section{A análise dos dados}

Os dados foram analisados por meio de análise estatística descritiva e por teste de hipótese, sendo utilizado o teste $\mathrm{t}$ de Student para dados pareados. O Método III foi considerado como testemunha devido à medição integral dos parâmetros mensuráveis. Deste modo, as diferenças observadas no ato das comparações com os Métodos I e II foram consideradas como discrepâncias.

A forma descritiva foi utilizada para estabelecer comparações entre as características, bem como entre as estimativas dos vários parâmetros avaliados em cada um dos três métodos. Complementando a análise dos dados, foi utilizado o teste $t$ de Student para o caso de duas amostras relacionadas. Este teste é utilizado para analisar duas populações dependentes, como representa o caso em questão.

As comparações de médias foram realizadas confrontando o Método III (testemunha) com o Método I e posteriormente com o Método II.

\section{RESULTADOS E DISCUSSÃO}

\section{Composição da arborização da área amostrada}

O levantamento contemplou um total de 728 indivíduos distribuídos em 53 espécies e 28 famílias botânicas. As cinco espécies que apresentaram maior freqüência foram: Michelia champaca $(16,4 \%)$, Bauhinia variegata (12,4\%), Ligustrum japonicum $(11,7 \%)$, Murraya exotica $(10,7 \%)$ e Caesalpinia peltophoroides $(9,7 \%)$. Estas representaram aproximadamente $61,0 \%$ da população amostrada.

É comum na arborização urbana, que poucas espécies representem a maior parte da população, mesmo não sendo uma situação desejável, quer por razões estéticas ou 
fitossanitárias (SILVA, 2000). Uma concentração maior de indivíduos distribuídos num pequeno número de espécies também foi encontrada por MILANO (1988), no inventário da cidade Maringá-PR, por ESPIRITO SANTO (1992) na cidade de Vitória-ES, por LIMA et al. (1994) na cidade de Piracicaba-SP e também na cidade de Porto Alegre-RS (PORTO ALEGRE, 2000).

De acordo com GREY e DENEKE (1986) é aconselhável que as espécies de maior freqüência não ultrapassem os $15 \%$, visto que porcentagens mais elevadas aumentam o risco da ocorrência de pragas e doenças.

\section{Avaliação da precisão dos métodos}

Os resultados obtidos mostraram que, quando se compara a precisão entre os três métodos testados, existem diferenças relativas e até significativas estatisticamente. Tais diferenças puderam ser observadas quando se comparou o Método III com os demais, ou seja, o Método I e o Método II.

\section{Comparação entre o Método III e o Método I}

Primeiramente foram abordados os parâmetros quantitativos, para os quais são apresentadas a discrepâncias totais, as subestimações e a superestimações. Em seguida, são tecidos comentários sobre os parâmetros avaliados qualitativamente.

Para o Método I, a leitura da altura total das árvores foi discrepante do Método III em $24,7 \%$ das vezes, sendo que em 10,8\%, o parâmetro foi subestimado e em 13,9\%, foi superestimado (Tabela 1 ). As estimativas foram submetidas ao teste t para dados pareados e apresentaram diferenças significativas entre as médias em nível de $5 \%$ de probabilidade, quando comparadas às respectivas leituras obtidas pelos Métodos III e I.

Observa-se que a porcentagem de discrepância total ficou relativamente bem distribuída entre subestimação e superestimação. Como no Método I os valores foram obtidos mediante a percepção do observador, é natural que parâmetros como altura total e diâmetro, que são difíceis de se avaliar visualmente de forma precisa, apresentem porcentagem de erro mais elevada em relação a outros parâmetros.

A distância do observador em relação à árvore influencia na sua percepção quanto à altura da mesma. Portanto, para melhor aproveitamento deste método, o avaliador deve procurar sempre fazer as leituras a uma mesma distância do objeto. 
Tabela 1 - Apresentação das porcentagens de discrepância das estimativas dos parâmetros avaliados pelo Método III e pelo Método I, utilizados na amostragem realizada nos bairros Horto e Sagrada Família em Belo Horizonte-MG.

\begin{tabular}{|l|c|c|c|}
\hline \multirow{2}{*}{ VARIÁVEL } & \multicolumn{3}{|c|}{ Método III x Método I } \\
\cline { 2 - 4 } & Discrepância total (\%) & Subestimação (\%) & Superestimação (\%) \\
\hline Altura total & 24,7 & 10,8 & 13,9 \\
\hline Altura $1^{\circ}$ bifurcação & 12,8 & 5,9 & 7,0 \\
\hline DAP & 26,2 & 9,9 & 16,3 \\
\hline Avanço da copa s/ rua & 17,7 & 11,7 & 6,0 \\
\hline Largura do passeio & 18,6 & 9,8 & 8,8 \\
\hline
\end{tabular}

Tabela 2 - Resultados do teste t, comparando as estimativas das médias dos Métodos III e I; oriundas da amostragem da arborização realizada nos bairros Horto e Sagrada Família em Belo Horizonte-MG.

\begin{tabular}{|l|c|c|}
\hline \multirow{2}{*}{ VARIÁVEL } & \multicolumn{2}{|c|}{ Médias } \\
\cline { 2 - 3 } & Método III & Método I \\
\hline Altura total & $7,7 \mathbf{a}$ & $7,6 \mathbf{b}$ \\
\hline Altura da $1^{\circ}$ bifurcação & $2,5 \mathbf{a}$ & $2,6 \mathbf{a}$ \\
\hline DAP & $27,3 \mathbf{a}$ & $27,9 \mathbf{b}$ \\
\hline Avanço copa sobre a rua & $3,1 \mathbf{a}$ & $2,9 \mathbf{a}$ \\
\hline Largura do passeio & $2,9 \mathbf{a}$ & $2,5 \mathbf{b}$ \\
\hline
\end{tabular}

Letras iguais em cada linha indicam igualdade entre os métodos pelo teste t para dados pareados em nível de 5\% de probabilidade.

A altura da primeira bifurcação apresentou uma discrepância total de 12,8\%, sendo $5,9 \%$ de subestimação e $7,0 \%$ de superestimação (Tabela 1 ), mas não apresentou diferença estatística pelo teste t, em nível de $5 \%$ de probabilidade (Tabela 2).

Neste caso, as discrepâncias também foram bem distribuídas entre subestimação e superestimação e a maioria das discordâncias em relação ao Método III aconteceu quase sempre com os valores próximos aos $2 \mathrm{~m}$, ou seja, próximo ao limite da classe estabelecida. Este parâmetro não apresentou dificuldade de avaliação.

O diâmetro do tronco (DAP) apresentou uma discrepância total de 26,2\%, tendo ocorrido subestimação em 9,9\% das vezes e superestimação em 16,3\% delas (Tabela 1). Quando submetido ao teste $\mathrm{t}$ para dados pareados, o referido parâmetro apresentou diferença significativa, em nível de $5 \%$ de probabilidade (Tabela 2 ). 
As medições foram realizadas com o avaliador posicionado próximo à árvore. Notase que a porcentagem de superestimação foi bem maior que a de subestimação, o que pode ter ocorrido devido à suposição de cilindricidade do tronco, no ato da avaliação.

Em relação ao avanço da copa sobre a rua, quando foram comparados os Métodos III e I, detectou-se uma subestimação de $11,7 \%$ e uma superestimação de $6,0 \%$, perfazendo uma discrepância total de 17,7\% (Tabela 1 ), que não se mostrou significativa pelo teste $\mathrm{t}$ para dados pareados, em nível de $5 \%$ de probabilidade (Tabela 2).

A porcentagem de subestimação foi de aproximadamente 0 dobro da superestimação. A diferença pode ter sido devida à diferença na largura das ruas. Quando as ruas apresentaram largura superior a 10 m, percebeu-se uma tendência de subestimação dos valores de avanço da copa e vice-versa.

Para a largura do passeio, foi observada uma discrepância total de 18,6\%, sendo que em $9,8 \%$ dos casos ocorreu a subestimação e em $8,8 \%$, a superestimação (Tabela 1). O teste t para dados pareados foi significativo em nível de $5 \%$ de probabilidade (Tabela 2).

Em relação aos parâmetros avaliados qualitativamente, o avanço da copa sobre a construção apresentou uma discrepância total de 2,2\%; para fitossanidade, a mesma foi de 3,3\%; para condição do sistema radicular foi de 3,4\% e para a área livre, a discrepância total foi de $1,1 \%$. Acredita-se que as porcentagens de erro apresentadas, mesmo pequenas quando comparadas àquelas avaliadas de forma quantitativa, ocorreram devido à própria subjetividade do método e, principalmente, nas proximidades dos limites das classes estabelecidas.

\section{Comparação entre o Método III e o Método II}

A altura total apresentou uma discrepância de 16,9\%, sendo $7,4 \%$ de subestimação e 9,5\% de superestimação. Em relação ao parâmetro altura da primeira bifurcação, a discrepância total foi de 7,4\%, com 3,2\% de subestimação e 4,4\% de superestimação. Já o DAP apresentou 15,2\% de discrepância total, sendo que em 4,9\% dos casos ocorreu a subestimação dos valores e em 10,3\%, a superestimação. Nas medições do avanço da copa sobre a rua, houve discrepância em 9,9\% dos casos, sendo que a subestimação foi de $6,5 \%$ e a superestimação, de 3,4\%. Para a largura do passeio, a discrepância total foi de 9,3\%, com subestimação de $4,5 \%$ e superestimação de $4,8 \%$ (Tabela 3 ). 
Tabela 3 - Apresentação das porcentagens de discrepância das estimativas dos parâmetros avaliados pelo Método III e pelo Método II, utilizados na amostragem realizada nos bairros Horto e Sagrada Família em Belo Horizonte-MG.

\begin{tabular}{|l|c|c|c|}
\hline \multirow{2}{*}{ VARIÁVEL } & \multicolumn{3}{|c|}{ Método III x Método II } \\
\cline { 2 - 4 } & Discrepância total (\%) & Subestimação (\%) & Superestimação (\%) \\
\hline Altura total & 16,9 & 7,4 & 9,5 \\
\hline Altura 1 ${ }^{\circ}$ bifurcação & 7,4 & 3,2 & 4,4 \\
\hline DAP & 15,2 & 4,9 & 10,3 \\
\hline Avanço da copa s/ rua & 9,9 & 6,5 & 3,4 \\
\hline Largura do passeio & 9,3 & 4,5 & 4,8 \\
\hline
\end{tabular}

A altura total, altura da primeira bifurcação, DAP, avanço da copa sobre a rua e largura do passeio foram submetidos ao teste t para dados pareados em nível de $5 \%$ de probabilidade, comparando-se os valores obtidos no Método III com aqueles obtidos pelo Método II. Apenas para a largura do passeio, obteve-se diferença significativa entre médias (Tabela 4).

Tabela 4 - Resultados do teste t, comparando as estimativas das médias dos Métodos III e II; oriundas da amostragem da arborização realizada nos bairros Horto e Sagrada Família em Belo Horizonte-MG.

\begin{tabular}{|l|c|c|}
\hline \multirow{2}{*}{ VARIÁVEL } & \multicolumn{2}{|c|}{ Médias } \\
\cline { 2 - 3 } & Método III & Método II \\
\hline Altura total & $7,7 \mathbf{a}$ & $7,6 \mathbf{a}$ \\
\hline Altura da 1 ${ }^{\circ}$ bifurcação & $2,5 \mathbf{a}$ & $2,6 \mathbf{a}$ \\
\hline DAP & $27,3 \mathbf{a}$ & $27,7 \mathbf{a}$ \\
\hline Avanço copa s/ a rua & $3,1 \mathbf{a}$ & $3,0 \mathbf{a}$ \\
\hline Largura do passeio & $2,9 \mathbf{a}$ & $2,7 \mathbf{b}$ \\
\hline
\end{tabular}

Letras iguais em cada linha indicam igualdade entre os métodos pelo teste $t$ para dados pareados em nível de 5\% de probabilidade.

Os parâmetros avanço da copa sobre a construção, fitossanidade, condição do sistema radicular e área livre, avaliados qualitativamente, mostraram resultados semelhantes àqueles obtidos pelo Método I, todos apresentando baixa porcentagem de erro, que se acredita ter sido causada pela própria subjetividade do método de avaliação.

Assim como na comparação do Método III com o Método I, a sua comparação com o Método II mostrou novamente que os parâmetros altura total e DAP apresentaram as 
maiores variações, ou seja, maiores porcentagens de discrepância total. Acredita-se que a porcentagem de discrepância obtida para a altura total tenha sido influenciada pela variação na altura das estruturas, que serviram de referência para a tomada das medições.

\section{Considerações sobre o Método I e o Método II}

Ao se comparar a discrepância da leitura da altura total e do DAP, ambas obtidas pelo Método I, com aquelas obtidas pelo Método II, pode-se perceber que houve uma queda significativa na discrepância total, ou seja, ocorreu um aumento da precisão de um método para outro, sendo que esta foi mais evidente com relação as medições de DAP (Tabelas 1 e 3). A reduzida melhoria de precisão em relação às medições de altura total pode ter ocorrido devido à variação existente nas alturas de postes e redes elétricas, que foram usados como referência para se proceder à leitura, quando foi utilizado o Método II. Cabe ressaltar que para o Método I, não se fez uso de tais elementos referenciais.

Os parâmetros avanço da copa sobre a rua e largura do passeio também apresentaram uma melhoria significativa da precisão quando foram comparadas as discrepâncias totais obtidas pelo Método e pelo Método II (Tabela1 e 3).

\section{Avaliação do tempo gasto na mensuração}

O tempo gasto na mensuração dos parâmetros quali-quantitativos dos indivíduos amostrados é apresentado destacando-se cada um dos métodos utilizados. Cabe ressaltar que para o Método III, as tomadas de tempo não terminaram no campo, uma vez que posteriormente, foram realizados cálculos para conversão dos valores de CAP para DAP. A soma dos tempos de campo e escritório estão representados no Tabela 5.

Tabela 5 - Apresentação do tempo total gasto para execução de cada método e o tempo gasto para mensurar uma única árvore em cada um dos métodos utilizados.

\begin{tabular}{|c|c|c|}
\hline Métodos & Tempo total & Tempo por árvore \\
\hline Método I & $10 \mathrm{~h} 57 \mathrm{~min} .56 \mathrm{~s}$ & $54,23 \mathrm{~s}$ \\
\hline Método II & $17 \mathrm{~h} 16 \mathrm{~min} .50 \mathrm{~s}$ & $85,45 \mathrm{~s}$ \\
\hline Método III & $26 \mathrm{~h} 12 \min .51 \mathrm{~s}$ & $129,63 \mathrm{~s}$ \\
\hline
\end{tabular}

Não foram computados os tempos de deslocamento do escritório até o campo e nem o tempo de deslocamento de uma árvore para outra, considerados constantes, visto que seriam os mesmos, independentemente do método utilizado. Computou-se apenas o tempo gasto efetivamente na medição.

Como pode ser observado no Tabela 5, o tempo gasto para a obtenção dos valores apresentou diferenças marcantes de um método para outro. Tal fato foi confirmado 
estatisticamente quando da aplicação do teste t para dados pareados. Este mostrou que as médias testadas apresentaram diferença significativa em nível de 5\% de probabilidade (Tabelas 6 e 7).

Tabela 6 - Resultados do teste t para dados pareados, comparando as estimativas das médias dos Métodos I e III, originárias da amostragem da arborização viária dos bairros Horto e Sagrada Família em Belo Horizonte-MG.

\begin{tabular}{|c|c|}
\hline Métodos & Tempo médio gasto por árvore \\
\hline Método I & $54,23 \mathbf{a}$ \\
\hline Método III & $117,20 \mathbf{~ b}$ \\
\hline
\end{tabular}

Tabela 7 - Resultados do teste t para dados pareados, comparando as estimativas das médias dos Métodos II e III, originárias da amostragem da arborização viária dos bairros Horto e Sagrada Família em Belo Horizonte-MG.

\begin{tabular}{|c|c|}
\hline Métodos & Tempo médio gasto por árvore \\
\hline Método II & $85,45 \mathbf{a}$ \\
\hline Método III & $117,20 \mathbf{b}$ \\
\hline
\end{tabular}

A execução do Método I foi 2,4 vezes mais rápida que o Método III e 1,6 vezes mais rápida que o Método II. Já o tempo gasto na realização do Método II foi 1,5 vezes menor do que aquele gasto na realização do Método III.

\section{Avaliação dos recursos gastos}

Os métodos diferiram entre si pela quantidade de equipamentos necessários para execução do serviço e quanto à quantidade de recursos humanos empregada.

O Tabela 8 apresenta os valores relativos em Reais $(R \$)$, dos recursos necessários para a formação da equipe de trabalho e compra dos equipamentos utilizados para cada um dos métodos avaliados. Foram considerados o trabalho das equipes e o tempo médio gasto para a execução de cada um dos métodos. 
Tabela 8 - Custos relativos para a formação das equipes de trabalho e execução de cada um dos três métodos de inventário empregados na amostragem da arborização viária dos bairros Horto e Sagrada Família em Belo Horizonte-MG.

\begin{tabular}{|l|c|c|c|c|c|}
\hline \multirow{2}{*}{ Método } & \multicolumn{2}{|l|}{ Mão-de-obra* } & \multicolumn{2}{l|}{ Equipamento } & \multirow{2}{*}{ Total } \\
\cline { 2 - 5 } & Técnico & Estagiários & Trenas & Régua & \\
\hline Método III & $1.700,00$ & 400,00 & 45,00 & $1.660,00$ & $3.805,00$ \\
\hline Método II & $1.133,33$ & 266,67 & 45,00 & -- & $1.445,00$ \\
\hline Método I & 708,33 & -- & -- & -- & 708,33 \\
\hline
\end{tabular}

* Considerando o salário mínimo no valor de $R \$ 200,00$ pago a cada estagiário e o piso

mínimo do técnico de nível superior equivalente a 8,5 salários mínimo.

Tomando como base os 728 indivíduos amostrados para avaliação dos métodos de inventário abordados neste trabalho, os valores do Tabela 8 mostraram que os custos totais para a realização do Método III foram 5,4 vezes mais elevados que os custos para a realização do Método I e 2,6 vezes maiores do que para o Método II. Já o Método II se mostrou duas vezes mais caro que o Método I.

A diferença entre os custos de cada método pode ser considerada expressiva. $O$ preço do equipamento foi responsável por boa parte dessa diferença, mas quando o equipamento apresenta boa durabilidade relativa, tais custos tendem a se diluir no tempo.

Supondo que as 728 árvores amostradas pudessem ser mensuradas em um único mês pelos 3 métodos, então a medição de uma árvore custaria $R \$ 5,22$ pelo Método III, $R \$$ 1,98 quando utilizado o Método II e R \$ 0,97 utilizando o Método I.

Cabe lembrar que nestas aproximações só foi considerado o tempo efetivo de medição da árvore, não tendo sido considerados o tempo de deslocamento de uma árvore para outra, deslocamento do escritório ao local das parcelas, combustível e outros.

\section{CONCLUSÕES}

Verificou-se que a estimação de parte dos dados do inventário, como no caso do Método II, pode reduzir os custos do levantamento e ao mesmo tempo manter a precisão dentro dos limites aceitáveis. Isto pode ser visto através das comparações realizadas entre os Métodos II e III.

A diferença observada entre o tempo de mensuração de um método para outro foi significativa estatisticamente e afetou diretamente o custo final do levantamento, mostrando que quanto mais tempo for gasto para se medir uma árvore, tanto mais dispendiosa será a realização do inventário.

As maiores discrepâncias observadas ocorreram nas avaliações dos parâmetros DAP e altura total realizadas pelo Método I, ambas em torno de $25 \%$. Além do fato de não 
se ter feito uso de instrumentos de medição, um fator que colaborou para o incremento da discrepância nas medições de DAP foi a suposição de cilindricidade do tronco. Já para as avaliações de altura, a variação na altura das estruturas de referência, dificultou uma avaliação mais precisa desse parâmetro.

Com base nas informações obtidas sobre os métodos, pode-se concluir que o Método I é mais indicado para os casos onde se deseja conhecer o patrimônio arbóreo, mas sem muita precisão com relação às características quantitativas tais como porte da árvore, diâmetro de copa e afastamento predial. A vantagem principal é a rapidez e o custo reduzido.

O Método II apresenta boa precisão e custo intermediário. Pode ser usado quando se deseja conhecer o patrimônio arbóreo, bem como obter informações quali-quantitativas seguras, que podem ser utilizadas para definir as práticas de manejo da arborização.

Já o Método III, é indicado quando se necessita de uma precisão elevada, como na realização de trabalhos científicos e estudos comparativos entre métodos.

\section{REFERÊNCIAS BIBLIOGRÁFICAS}

CENCIC, A. Estudo da paisagem cultural - o Campus da Universidade Federal de Minas Gerais. Belo Horizonte: UFMG/IGC, 1996. 356 p. Dissertação (Mestrado em Geografia) - Universidade Federal de Minas Gerais, 1996.

ESPÍRITO SANTO. Prefeitura Municipal VitórialSecretaria Municipal de Meio AmbientelSecretaria Municipal de Serviços Urbanos. Plano diretor de arborização e áreas verdes. Vitória, 1992. 98 p.

GREY, G. W., DENEKE, F. J. Urban forestry. New York, John Wiley \& Sons, 1986. 279 p.

LIMA, A. M. L. P., COUTO, H. T. Z., ROXO, J. L. C. Análise de espécies mais freqüentes da arborização viária, na zona urbana central do município de Piracicaba/SP. In: CONGRESSO BRASILEIRO DE ARBORIZAÇÃO URBANA, 2, 1994, São Luis. Anais... São Luís, 1994. p. $555-573$.

MILANO, M.S. Avaliação quali-quntitativa e manejo da arborização urbana: exemplo de Maringá. Curitiba: UFPR, 1988. 120 p. Tese (Doutorado em Engenharia Florestal) Universidade Federal do Paraná, 1988. 
MILLER, W. R. Urban forestry - planning and managing urban greenspaces. 2.ed. New Jersey: Prentice-Hall, 1997. 502 p.

PORTO ALEGRE. Secretaria Municipal do Meio Ambiente. Plano Diretor de Arborização de Vias Públicas. Porto Alegre, 2000. 204 p.

SANTOS, E. Avaliação quali-quantitativa da arborização e comparação econômica entre a poda e a substituição da rede de distribuição de energia elétrica da Região Administrativa Centro-Sul de Belo Horizonte-MG. Viçosa, MG: UFV, 2001. 219 p. Tese (Doutorado em Ciência Florestal) - Universidade Federal de Viçosa, 2001.

SILVA, A. G. Avaliação da arborização no perímetro urbano de Cajuri-MG, pelo Método do Tabela Sintético. Viçosa, MG: UFV, 2000. 150 p. Dissertação (Mestrado em Ciência Florestal) - Universidade Federal de Viçosa, 2000.

TAKAHASHI, L.Y. Arborização urbana: inventário. In: CONGRESSO BRASILEIRO SOBRE ARBORIZAÇÃO URBANA, 2, São Luiz, 1994. Anais... São Luiz: SBAU, 1994. p. 193-199.

TAKAHASHI, L.Y. Controle e monitoramento de arborização urbana. In: ENCONTRO NACIONAL SOBRE ARBORIZAÇÃO URBANA, 3., Curitiba. 1990. Anais... Curitiba: [s.n.], 1990. p. 115 - 123. 